\title{
Disposition and effect of intra-articularly administered dexamethasone on lipopolysaccharide induced equine synovitis
}

Carl Ekstrand ${ }^{1 *} \mathbb{D}$, Ulf Bondesson²,3, Ellen Giving ${ }^{4}$, Mikael Hedeland $^{2,3}$, Carina Ingvast-Larsson ${ }^{1}$, Stine Jacobsen ${ }^{5}$, Maria Löfgren', Lars Moen ${ }^{4}$, Marie Rhodin' ${ }^{6}$, Tonje Saetra ${ }^{7}$ and Birgit Ranheim ${ }^{8}$

\begin{abstract}
Background: Dexamethasone is used for the intra-articular route of administration in management of aseptic arthritis in horses. Despite its widespread use there is very little quantitative data of the disposition and response to dexamethasone. The aim of this study was to investigate and describe the synovial fluid and plasma dexamethasone concentration over time and to explore the relation between synovial fluid concentration and response using clinical endpoints as response biomarkers after IA injection of dexamethasone disodium salt solution in an equine model of synovitis.
\end{abstract}

Results: Inflammation was induced in the radiocarpal joint of six horses by injection of $2 \mathrm{ng}$ lipopolysaccharide (LPS). Two hours later either saline or dexamethasone was injected in the same joint in a two treatment cross over design. Each horse was treated once with one of the six doses dexamethasone used $(0.01,0.03,0.1,0.3,1$ or $3 \mathrm{mg})$ and once with saline. Dexamethasone was quantified by means of UHPLC-MS/MS. Dexamethasone disposition was characterised by means of a non-linear mixed effects model. Lameness was evaluated both objectively with an inertial sensor based system and subjectively scored using a numerical scale (0-5). Joint circumference, skin temperature over the joint and rectal temperature were also recorded. The LPS-challenge induced lameness in all horses with high interindividual variability. Dexamethasone significantly decreased lameness compared with saline. Other variables were not statistically significant different between treatments. Objective lameness scoring was the most sensitive method used in this study to evaluate the lameness response. A pharmacokinetic/pharmacodynamic model was successfully fitted to experimental dexamethasone and lameness data. The model allowed characterization of the dexamethasone synovial fluid concentration-time course, the systemic exposure to dexamethasone after intra-articular administration and the concentration-response relation in an experimental model of synovitis.

Conclusions: The quantitative data improve the understanding of the pharmacology of dexamethasone and might serve as input for future experiments and possibly contribute to maintain integrity of equine sports.

Keywords: Corticosteroids, Pharmacokinetics, Pharmacodynamics, Quantitative pharmacology

\footnotetext{
*Correspondence: carl.ekstrand@slu.se

${ }^{1}$ Department of Biomedical Sciences and Veterinary Public Health, Faculty of Veterinary Medicine and Animal Science, Swedish University

of Agricultural Sciences, Box 7058, 75007 Uppsala, Sweden

Full list of author information is available at the end of the article
} 


\section{Background}

Joint injury or disease is common in both equine athletes and companion horses. In racehorses, the overall injury rate was estimated to 1.8 injuries per 100 months the horses were at risk for injuries, i.e. from entering the study until diagnosed with an injury [1]. Also, one-third of euthanised 2- to 3-year-old thoroughbred racehorses were diagnosed post mortem with metacarpophalangeal joint arthritis [2]. Intra-articular (IA) injections of glucocorticoids are routinely used in the treatment of equine joint disease. Both clinical studies and experimental studies demonstrate the effectiveness of glucocorticoids in the inflamed joint [3-7]. The effect of dexamethasone administered both intravenously (IV) and IA has been investigated after lipopolysaccharide (LPS) challenge of the equine joint using total protein concentration in synovial fluid as response biomarker [5]. However, that study only compared the effect after IV and IA administration and did not report any dexamethasone plasma nor synovial fluid concentrations of dexamethasone. Synovial fluid concentrations and plasma disposition has been described for several glucocorticoids after IA administration to healthy joints [8-17]. This quantitative information might also be used in anti-doping and medication control to assess irrelevant drug concentrations, which protect both animal welfare and the integrity of racing and equestrian sports $[18,19]$. However, the disposition of dexamethasone in synovial fluid from inflamed joint has not been reported. The aim of this study was to investigate and describe the synovial fluid and plasma dexamethasone concentration over time and to explore the relation between synovial fluid concentration and response using clinical endpoints as response biomarkers after IA injection of dexamethasone disodium salt solution in an equine model of synovitis.

\section{Methods}

\section{Animals}

Three Standardbred mares and three Standardbred geldings (horses A-F), 3-9 years old and weighing 429$550 \mathrm{~kg}$, were included in the study. Immediately before collection of baseline data no signs of radiocarpal joint inflammation (joint effusion, heat) was detected upon clinical examination and front leg lameness was 1.5 or less (American Association of Equine Practitioners lameness scale) during baseline collection.

\section{Experimental design and intra-articular injections}

This study was prospective, randomised, placebo-controlled and blinded. Three days before treatment, the horses were transported to the study location for acclimatisation. The horses were assigned to an experiment including two treatments, LPS + dexamethasone 21-phosphate disodium salt solution (DSP, Dexadreson, $2 \mathrm{mg} / \mathrm{mL}$, Intervet AB, Sollentuna, Sweden) and for control LPS + saline was administered in the contralateral joint. Dexamethasone dose and treatment regimen is shown in Table 1.

During experimental periods, the horses were kept in individual boxes and fed hay and concentrate (Champion komplett, Felleskjøpet, Lillestrøm, Norway). Water was available ad libitum. During wash-out periods the horses were on pasture. Before treatment, the hair over the jugular vein was clipped and the skin was disinfected with chlorhexidine solution and 70\% ethanol. One $2.1 \times 130 \mathrm{~mm}$ intravenous catheter (MILA International Inc., Florence, KY, USA) was placed in the jugular vein and secured with three sutures. Before arthrocentesis, the hair over the radiocarpal joint was clipped and the skin was disinfected with chlorhexidine solution and $70 \%$ ethanol.

Inflammation was induced in the radiocarpal joint by means of LPS from Escherichia coli 055:B5 purified by phenol extraction (Product Number L2880) (SigmaAldrich). A stock solution was prepared by diluting the LPS in sterile water. In a second step, the LPS was diluted in sterile physiological saline to a concentration of $1 \mathrm{ng} /$ $\mathrm{mL}$. Aliquots were frozen at $-70{ }^{\circ} \mathrm{C}$ in siliconised tubes, thawed and vortexed for $15 \mathrm{~min}$ immediately before use, according to the manufacturer's instructions. A total volume of $2 \mathrm{~mL}$ LPS solution was injected into the joint at time 0 using a glass syringe (Hamilton Company, Timis,

Table 1 Dose and treatment regimen

\begin{tabular}{|c|c|c|c|c|c|}
\hline Horse & Dose (mg) & Treatment \#1 & Limb & Treatment \#2 & Limb \\
\hline A & 0.3 & LPS + dexamethasone & RF & LPS + saline & LF \\
\hline B & 0.1 & LPS + saline & LF & LPS + dexamethasone & RF \\
\hline C & 0.03 & LPS + saline & RF & LPS + dexamethasone & LF \\
\hline $\mathrm{D}$ & 1 & LPS + saline & LF & LPS + dexamethasone & RF \\
\hline$E$ & 3 & LPS + saline & RF & LPS + dexamethasone & LF \\
\hline$F$ & 0.01 & LPS + dexamethasone & LF & LPS + saline & RF \\
\hline
\end{tabular}

$L F$ left front, $R F$ right front 
Romania). Two hours after LPS injection, equivalent volumes $(2 \mathrm{~mL})$ of either $0.9 \%$ saline or DSP diluted in saline were injected into the joint. All joint injections and samplings were performed using $0.8 \times 35 \mathrm{~mm}$ needles. Each of the six horses was treated with one dose dexamethasone injected once into the radiocarpal joint during LPS + DSP treatment. A minimum of 3 weeks wash-out period was applied between treatments. A nose twitch was applied before injections and collection of synovial fluid in order to restrict the horse from sudden movements. The study was approved by the Norwegian Animal Research Authority (Forsøksdyrutvalget 2013/61618-1).

\section{Sampling protocol}

Synovial fluid samples and plasma samples for drug concentration determination were collected at time -2 (before LPS injection) and 0 (before DSP or saline injection), 2, 4, 8, 22, 26, 30, 46, 50, 54, 70 and $74 \mathrm{~h}$ after DSP and saline injection. Three additional blood samples were also drawn at 5, 20 and $40 \mathrm{~min}$ after DSP and saline injection. Immediately before injection or sampling the skin over the joint was desensitised by means of a cooling spray (Articare Cold Spray, BSN Medical Ltd. Hull, UK). Blood and synovia were centrifuged at $1800 \mathrm{~g}$ for 10 and $5 \mathrm{~min}$, respectively. The supernatant was transferred to microcentrifuge tubes and immediately frozen at $-20{ }^{\circ} \mathrm{C}$, moved within $24 \mathrm{~h}$ and stored at $-70{ }^{\circ} \mathrm{C}$ pending analysis.

Clinical endpoints (CEs) baseline was recorded three times, typically between 15.00 and 18.00 the day before LPS challenge. CEs were also recorded before collection of synovial fluid and at one additional occasion $6 \mathrm{~h}$ after dexamethasone administration. The CEs were: rectal temperature (RT) measured by means of a digital thermometer, local skin temperature (ST) measured by means of a digital infrared thermometer (Fluke 574 cf, SR Automation AS, Asker, Norway) and joint-circumference (JC) measured by means of a measuring-tape. Lameness was evaluated in trot $(8 \times 20 \mathrm{~m}$ in a straight line on flat concrete floor indoors). Lameness was subjectively scored by three experienced clinicians using the American Association of Equine Practitioners (AAEP) lameness scale. Objective lameness analysis was performed by means of a commercial inertial measure unit based gait analysis system (Lameness Locator ${ }^{\circledR}$, Equinosis, St. Louis, MO, USA) for lameness detection [20]. Two uni-axial accelerometer was used. One was mounted to a head bumper attached to the bridle over the poll and one was taped to the midline of the pelvis at the level of the tubera sacrale. One uni-axial gyroscope was attached dorsally to the proximal and middle phalanges of the right forelimb for stride segmentation. Vertical uni-axial acceleration was recorded at $200 \mathrm{~Hz}$ and data were transmitted wirelessly from the sensors to a computer running the data collection software. Objective motion data were processed with the software package for the gait analysis system. Raw uni-axial acceleration signals from head and pelvis sensors, aligned with the global vertical axis in the standing position, were first transformed into displacement signals using a custom-designed, error-correcting, double-integration technique and the signal from the right forelimb gyroscope [20]. From the displacement signal local minima of the head were identified (two per stride). Forelimb impact lameness was measured by means of differences between the two local minima $\left(\mathrm{HD}_{\min }\right)$ during left and right stance phases, computed for each stride. Results are reported as change in absolute $\mathrm{HD}_{\text {min }}$ values from baseline.

\section{Dexamethasone IV-data}

Dexamethasone plasma concentration-time data from a previous study [21] was used in the pharmacokinetic analyses in order to increase the data-set. In that study six Standardbred horses (four mares and two geldings) 6-20 years old and weighing $430-584 \mathrm{~kg}$ were used in a randomized crossover design including three treatments with dexamethasone at various doses. Each treatment started with an intravenous bolus dose immediately followed by $3 \mathrm{~h}$ of constant rate infusion of dexamethasone 21-phosphate disodium salt (Dexadreson $2 \mathrm{mg} /$ $\mathrm{mL}$, Intervet $\mathrm{AB}$, Sollentuna, Sweden). The dose levels were (bolus + infusion) $0.1+0.07 \mu \mathrm{g} / \mathrm{kg}, 1+0.7 \mu \mathrm{g} / \mathrm{kg}$ and $10+7 \mu \mathrm{g} / \mathrm{kg}$ dexamethasone. Before the bolus dose $($ time $=0)$ a pre-dose blood sample was drawn. Additional blood samples were drawn during and after infusion at hours $1,2,3,4,5,6,9,12,18,24,36$ and 48. A minimum of a 1-week wash-out period was allowed between drug treatments.

\section{Dexamethasone quantification}

Plasma and synovial fluid dexamethasone concentrations were analysed and quantified with the use of ultra high performance liquid chromatography-tandem mass spectrometry (UHPLC-MS/MS). Dexamethasone reference compound was acquired from Toronto Research Chemicals (North York, ON, Canada) and the internal standard ${ }^{2} \mathrm{H}_{4}$-dexamethasone (dexamethasone-d4) was purchased from CDN Isotopes through QMX Laboratories Ltd. (Essex, UK). The water was purified using a Milli-Q water purification system (Millipore, Bedford, MA, USA). All other chemicals were of analytical grade or better and used without further purification. Synovial fluid from control treatment was used as blank matrix for preparations of calibrators and control samples (QC). 
Samples were pretreated by diluting each synovial sample $(50 \mu \mathrm{L})$ with $950 \mu \mathrm{L}$ of aqueous potassium phosphate buffer $(0.1 \mathrm{M}, \mathrm{pH}$ 6.05). To $100 \mu \mathrm{L}$ of the diluted sample, $50 \mu \mathrm{L}$ of the internal standard (dexamethasone$\mathrm{d} 4,0.05 \mu \mathrm{g} / \mathrm{mL}), 500 \mu \mathrm{L}$ of potassium phosphate buffer (0.1 M, pH 6.05) were added. Liquid-liquid extraction was carried out to $2.0 \mathrm{~mL}$ tert-butylmethylether by vortex mixing for $5 \mathrm{~min}$ and subsequent centrifugation for $10 \mathrm{~min}$. To facilitate phase separation, the samples were then frozen at $-70{ }^{\circ} \mathrm{C}$ for $30 \mathrm{~min}$ after which the organic phase was decanted to another tube and evaporated under a gentle stream of air at $55{ }^{\circ} \mathrm{C}$. The samples were reconstituted in $100 \mu \mathrm{L}$ of aqueous formic acid (0.1\%)/ methanol $(1: 1 \mathrm{v} / \mathrm{v})$ and transferred to vials for UHPLCMS/MS analysis.

The extracts were analyzed with UHPLC-MS/MS. A Waters Acquity UPLC system was coupled to a Quattro Ultima Pt tandem quadrupole mass spectrometer with an electrospray interface operating in the positive mode (Waters Corporation, Milford, MA). The column was an Acquity UPLC BEH C18 (length 100 mm, I.D. $2.1 \mathrm{~mm}$, particle size $1.7 \mu \mathrm{m}$ ) from Waters Corporation kept at $65{ }^{\circ} \mathrm{C}$. The mobile phase consisted of (A) ammonium acetate (aq, $2.0 \mathrm{mM}$ ) and (B) formic acid (0.1\%) in acetonitrile. A gradient was run as follows: initially $23 \%$ B for $4.7 \mathrm{~min}, 23-90 \% \mathrm{~B}$ in $0.1 \mathrm{~min}$, constant at $90 \% \mathrm{~B}$ for $1.0 \mathrm{~min}, 90-23 \% \mathrm{~B}$ in $0.1 \mathrm{~min}$, constant at $23 \% \mathrm{~B}$ for $0.9 \mathrm{~min}$. The total run time was $6.8 \mathrm{~min}$, the flow rate was $650 \mu \mathrm{L} / \mathrm{min}$ and the injection volume was $10 \mu \mathrm{L}$.

The mass spectrometric settings were as follows: a positive capillary voltage of $3.5 \mathrm{kV}$, the desolvation and source block temperatures were $300{ }^{\circ} \mathrm{C}$ and $120{ }^{\circ} \mathrm{C}$ and the cone and desolvation gas flows were 121 and $830 \mathrm{~L} / \mathrm{h}$, respectively. The quantifications were performed in the selected reaction monitoring (SRM) mode with the collision cell filled with argon gas at a pressure of $2.4 \times 10^{-3} \mathrm{mBar}$. The transitions used in SRM were $m / z 393 \rightarrow 355$ for dexamethasone (collision energy $14 \mathrm{eV}$, cone voltage $50 \mathrm{~V}$ ) and $m / z 397 \rightarrow 359$ for dexamethasone-d4 (collision energy $14 \mathrm{eV}$, cone voltage $50 \mathrm{~V}$ ). The dwell time was $0.01 \mathrm{~s}$.

Stock solutions of dexamethasone, and the internal standard were prepared in methanol at approximately $0.3 \mathrm{mg} / \mathrm{mL}$. These solutions were diluted and used to spike blank synovial fluid to obtain calibration and QC samples. The calibration was performed by linear curve fit (weighting factor of $1 / \mathrm{x}^{2}$ ) of the peak area ratio (analyte/internal standard) as a function of the analyte concentration. The LLOQ for dexamethasone in synovial fluid was $0.38 \mathrm{ng} / \mathrm{mL}$. The precision expressed as the relative standard deviation (RSD) in the results of quality control samples in synovia was in the interval $2.7-7.8 \%$ and the accuracy was in the range of $97-109 \%$.
The analytical method for dexamethasone in plasma is further described in our previous work [22]. The lower limit of quantification (LLOQ) for dexamethasone in plasma was $0.025 \mathrm{ng} / \mathrm{mL}$.

\section{Dexamethasone concentration-time analyses}

A non-linear mixed effects (NLME) approach that is the appropriate tool [23] to analyse unbalanced data set obtained in different trials was used to estimate pharmacokinetic and pharmacodynamic parameters. A comprehensive three compartment model (Fig. 1) was fitted to the dexamethasone synovial fluid concentration-time data from the six horses in the current study and to the dexamethasone plasma concentration-time data in the current study and from the study in [21]. The disposition of dexamethasone in synovial fluid was described as:

$$
\frac{d A m t_{s y n}}{d_{t}}=\left[A m t_{p} \cdot k_{p a}-A m t_{s y n} \cdot k_{a p}\right]-\left[A m t_{s y n} \cdot k_{e l}\right]
$$

where $A m t_{\text {syn }}$ and $A m t_{p}$ are the dexamethasone amount in synovial fluid and in plasma, respectively. The $k_{p a}, k_{a p}$ and $k_{e l}$ are the first-order rate constants from plasma to synovial fluid, from synovial fluid to plasma and for direct elimination from the joint, respectively. The dexamethasone synovial fluid concentration $\left(C_{s y n}\right)$ was obtained by:

$$
C_{\text {syn }}=\frac{A m t_{\text {syn }}}{V_{\text {syn }}}
$$

For identifiability reason, the average volume of the synovial compartment $\left(V_{\text {syn }}\right)$ was fixed at $0.2 \mathrm{~mL} / \mathrm{kg}$ and the individual value for each horse $\left(V_{\text {horse }}\right)$ was obtained by:

$$
V_{\text {horse }}=0.2 \cdot e^{\eta_{\text {horse }}}
$$

where $\eta_{\text {horse }}$ is the deviation of each horse from its (fixed) typical value.

The disposition of dexamethasone in the central compartment after IA administration of dexamethasone was described as:

$$
\begin{aligned}
\frac{d A m t_{p}}{d t}= & -\left[C l \cdot C_{p}\right]-C l_{d} \cdot\left[C_{p}-C_{t}\right] \\
& -\left[A m t_{p} \cdot k_{p a}-A m t_{s y n} \cdot k_{a p}\right]
\end{aligned}
$$

where $C_{p}$ and $C_{t}$ denote the dexamethasone concentration in synovial fluid, the central and peripheral compartment, respectively. $A m t_{s y n}, k_{p a}$ and $k_{a p}$ as defined in Eq. (1), $C l$ is the plasma clearance of dexamethasone and $\mathrm{Cl}_{d}$ is the inter-compartmental distribution. Dexamethasone disposition in the central compartment after IV administration of dexamethasone was described as: 


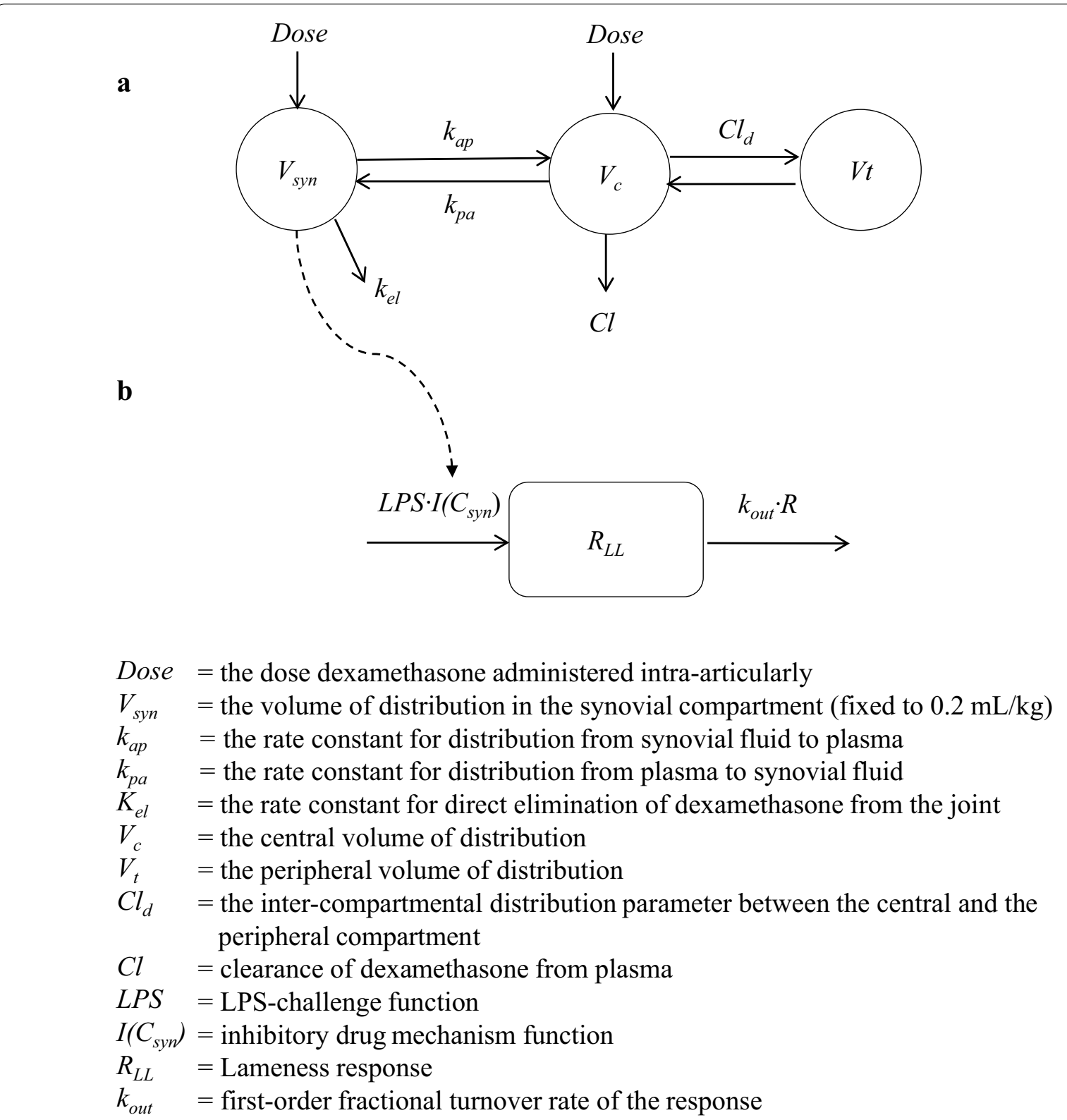

Fig. 1 Illustration of the sequential approach that was adopted to estimate the PK/PD parameters. The upper row shows the dexamethasone synovial fluid and plasma disposition model (a) and the lower row the pharmacodynamic model (b) describing the LPS challenge and lameness response $\left(R_{L L}\right)$. The post hoc estimates of individual PK parameters were fixed to their post hoc estimate to "drive" the drug-mechanism function $\left(/\left(C_{\text {syn }}\right)\right)$ acting on production of lameness response induced by the LPS-challenge [25]

$$
\frac{d A m t_{p}}{d t}=-\left[C l \cdot C_{p}\right]-C l_{d} \cdot\left[C_{p}-C_{t}\right]
$$

and the dexamethasone amount in the peripheral compartment $A m t_{t}$ was described as:

$$
A m t_{t}=C l_{d} \cdot\left(C_{p}-C_{t}\right)
$$

$$
C_{p}=\frac{A m t_{p}}{V_{c}}
$$

$$
C_{t}=\frac{A m t_{t}}{V_{t}}
$$

where $C_{p}$ and $C_{t}$ were obtained by Eqs. (7) and (8): 
where $V_{c}$ is the central volume of distribution, $V_{t}$ is the peripheral volume of distribution.

The between subject variability (BSV) was described using an exponential model of the form:

$$
\theta_{\text {parameter_ } i}=\theta_{t v \_ \text {parameter }} \cdot e^{\eta}
$$

where $\theta_{\text {parameter_i }}$ is the value of theta for respective parameter in the ith horse, $\theta_{t v \_ \text {parameter }}$ is the typical population value of the parameter (e.g. $V_{c}, V_{t}, C l, C l_{d}$ etc.) and $\eta_{i}$ is the deviation from the corresponding theta population value associated to the $i$ th horse. The exponential model assumes a log-normal distribution of parameters, i.e. that the distribution of the etas $\left(\eta_{i}\right)$ is normal in the $\log$-domain, with a mean of 0 and a variance $\omega^{2}$ where:

$$
\eta \approx N\left[0, \omega^{2}\right]
$$

Shrinkage of random effects toward the means according to Karlsson and Savic [24] was described as:

$$
\text { shrinkage }=1-\frac{S D\left(E B E_{\eta}\right)}{\omega}
$$

where $S D(E B E \eta)$ is the standard deviation of the individual values of the Empirical Bayesian Estimates (EBE) of $\eta$.

When the three compartment model was fitted to IVdata from the study in [21], clearance was assumed to possibly vary with dose and was considered as a covariate described as:

$$
C l=\theta_{t v C l} \cdot\left[1+\theta_{1} \text { dose }_{\text {level }}\right]
$$

where $\theta_{t v}, \theta_{1}$ and dose $_{\text {level }}$ are the typical value for clearance for a theoretical dose of $0, \theta_{1}$ reflect the change in clearance by dose level and the dose level, respectively.

From the model parameters following secondary parameters were derived:

The terminal slope $\left(\beta_{p}\right)$ of the dexamethasone plasma concentration-time course was described as:

$$
\begin{aligned}
\beta_{p}= & 0.5 \cdot\left[\frac{C l_{d}}{V_{c}}+\frac{C l_{d}}{V_{t}}+\frac{C l}{V_{c}}-\left[\left(\frac{C l_{d}}{V_{c}}+\frac{C l_{d}}{V_{t}}+\frac{C l}{V_{c}}\right)^{2}\right.\right. \\
& \left.\left.-4 \frac{C l_{d}}{V_{t}} \cdot \frac{C l}{V_{c}}\right]^{0.5}\right]
\end{aligned}
$$

The initial slope $\left(\alpha_{\mathrm{p}}\right)$ of the plasma dexamethasone concentration-time course was described as:

$$
\alpha_{p}=\frac{C l_{d}}{V_{t}} \cdot \frac{\frac{C l}{V_{c}}}{\beta}
$$

The terminal half-life $\left(t_{1 / 2 \beta}\right)$ of the plasma dexamethasone concentration-time course was described as:

$$
t_{1 / 2 \beta}=\frac{\ln 2}{\beta}
$$

The initial half-life $\left(t_{1 / 2 \alpha}\right)$ of the plasma dexamethasone concentration-time courses was described as:

$$
t_{1 / 2 \alpha}=\frac{\ln 2}{\alpha}
$$

\section{LPS-challenge model and lameness response analyses}

The LPS synovial concentration was not known and the time course of the challenge function $\left(S_{L P S}\right)$ was described as:

$$
\begin{aligned}
S_{L P S}= & {\left[A_{L P S 1} \cdot k_{L P S 1} \cdot t \cdot e^{-k_{L P S 1} \cdot t}\right]^{\gamma 1} } \\
& +\left[A_{L P S 2} \cdot k_{L P S 2} \cdot t \cdot e^{-k_{L P S 2} \cdot t}\right]^{\gamma 2}
\end{aligned}
$$

where $A_{L P S 1}, A_{L P S 2}, k_{L P S 1}$ and $k_{L P S 2}$ represent the maximal input rates and the rate constant controlling the time development of the challenge function. The gamma $\left(\gamma_{1}\right.$, $\gamma_{2}$ ) parameters are exponents amplifying the response to the challenge. The rate of change $\left(\frac{d R}{d t}\right)$ of lameness response measured by means of Lameness locator ${ }^{\circledR}$ was then described as follows:

$$
\frac{d R}{d t}=S_{L P S}-k_{\text {out }} \cdot R
$$

where $k_{\text {out }}$ and $R$ represent the fractional turnover rate of response and the lameness response.

Dexamethasone was assumed to inhibit lameness response to the LPS challenge. A sequential approach was adopted to estimate the PD parameters. The post hoc estimates of individual PK parameters were fixed to their post hoc estimate to 'drive' the inhibitory function [25]. The inhibitory function $\left(I\left(C_{s}\right)\right)$ was described as:

$$
I\left(C_{s}\right)=1-\frac{I_{\max } \cdot C_{s y n}}{I C_{50}+C_{s y n}}
$$

where $I_{\max }$ and $I C_{50}$ are the maximum drug-induced inhibition of lameness response and the dexamethasone synovial fluid concentration at 50\% reduction in the lameness response, respectively.

The drug mechanism function was then incorporated in Eq. (16) to give Eq. (18):

$$
\frac{d R}{d t}=S_{L P S} \cdot I\left(C_{s}\right)-k_{\text {out }} \cdot R
$$

Phoenix NLME version 8.0 (Certara, St. Louis, MO, USA) was used in regression of data. A multiplicative (proportional) error (weighting) model was used 
for weighting dexamethasone-time data and lameness response-time data.

\section{Statistics}

Independently of the PK/PD-modelling approach the data was subjected to conventional statistical hypothesis testing by means of a linear mixed-effects model. Time and dose were used as categorical fixed effects and horse as random effect. Data was compared between doses for every time-point. An ad hoc analysis (Dunnett's test) was performed in order to compare data after LPS administration with the pre-administration data. The repeated measures structure of the data was accounted for by including an autoregressive correlation structure on the error term within each individual. Statistical significance was considered when $\mathrm{P}<0.05$. All statistical analyses were performed using the statistical software $\mathrm{R}$ version 3.4.4 (The $\mathrm{R}$ Foundation for Statistical Computing, Vienna, Austria).

\section{Results}

\section{Disposition of dexamethasone}

In the horses receiving the four lower doses, dexamethasone was quantifiable (LLOQ $0.38 \mathrm{ng} / \mathrm{mL}$ ) in synovial fluid samples collected 2, 4 and $8 \mathrm{~h}$ after injection. In the horses receiving the two higher doses, dexamethasone was quantifiable up to $30 \mathrm{~h}$ (six samples) after injection (Fig. 2).

For horse $\mathrm{F}$ that received $0.01 \mathrm{mg}$ dexamethasone IA no dexamethasone plasma concentrations were quantifiable (LLOQ $0.025 \mathrm{ng} / \mathrm{mL}$ ). For horse $\mathrm{C}$ that received $0.03 \mathrm{mg}$, dexamethasone was only quantifiable in the samples collected 5 and 20 min after DSP injection (both $0.03 \mathrm{ng} / \mathrm{mL}$ ). In the horses receiving the four higher doses (Table 1) dexamethasone was quantifiable up to $24 \mathrm{~h}$ (5-7 plasma samples) and maximum concentration was observed within 40 min (Fig. 2).

A three-compartment model (including one compartment for synovial fluid) was fitted to experimental dexamethasone synovial fluid data and dexamethasone plasma data from all horses in this study and from literature plasma raw data collected from [21]. The model estimated and derived pharmacokinetic parameters from the horses in this study are shown in Table 2. Experimental dexamethasone data were evenly distributed around the line of unity for both the structural and the random component of the three compartment model (Fig. 3). The conditional weighted residuals (CWRES) over time were concentrated between $\mathrm{y}=-2$ and $\mathrm{y}=+2$ for dexamethasone plasma and synovial fluid concentrations (Fig. 4). The typical values for disposition in synovial fluid and plasma are given in Table 2. The typical value for total plasma clearance of dexamethasone was $246 \mathrm{~mL} / \mathrm{kg} / \mathrm{h}$.
For literature data from [21], dexamethasone was administered in three doses. Hence, dose was used as a covariate and clearance was $426 \mathrm{~mL} / \mathrm{kg} / \mathrm{h}$ and $428 \mathrm{~mL} / \mathrm{kg} / \mathrm{h}$ after administration of the intermediate and the high dose. The $t_{1 / 2 \alpha}$ and $t_{1 / 2 \beta}$ in plasma was $0.6 \mathrm{~h}$ and $4.3 \mathrm{~h}$. The fraction of the administered dose that was eliminated directly from the joint without gaining access to plasma for the first $48 \mathrm{~h}$ after administration was $0.5-2.1 \%$.

There were no differences in clinical endpoint baseline between the two treatment protocols. The LPS + saline treatment increased objective lameness score using objective $\left(\mathrm{HD}_{\min }\right)$ lameness data compared to baseline at $4 \mathrm{~h}(\mathrm{P}<0.001)$ and $6 \mathrm{~h}(\mathrm{P}<0.001)$ after LPS-administration. The LPS + DSP treatment did not increase lameness score compared to baseline using $\mathrm{HD}_{\text {min }}$ data. After treatment with LPS + DSP the horses were less lame at $4 \mathrm{~h}(\mathrm{P}$ $0.001), 6 \mathrm{~h}(\mathrm{P}=0.004)$ and $10 \mathrm{~h}(\mathrm{P}=0.04)$ compared to treatment with LPS + saline (Fig. 5a). The LPS + saline treatment increased subjective lameness score compared to baseline at $4 \mathrm{~h}(\mathrm{P}<0.001)$ and $6 \mathrm{~h}(\mathrm{P}<0.001)$ after LPSadministration. The LPS + DSP treatment increased subjective lameness score at $4 \mathrm{~h}(\mathrm{P}=0.008)$ compared to baseline. After treatment with LPS + DSP horses were less lame at $6 \mathrm{~h}(\mathrm{P}=0.008)$, compared to treatment with LPS + saline (Fig. 5b).

There was no difference in JC and ST between the two treatments. For RT no difference between the two treatments was observed from 0 to $72 \mathrm{~h}$. At $76 \mathrm{~h}$ RT was higher in the LPS + saline group $(P=0.03)$. No signs of septic arthritis were observed during or in the following days after LPS injection and sample collection.

Subjective and objective $\left(\mathrm{HD}_{\min }\right)$ lameness scores are shown in Fig. 5. The LPS-challenge + intra articular saline induced an increase in $\mathrm{HD}_{\min }$ (indicating impact lameness in the induced limb) in all horses compared to baseline. Median (range) $\mathrm{HD}_{\min }$ was $96 \mathrm{~mm}$ (12-196). The maximum $\mathrm{HD}_{\min }$ was observed within $8 \mathrm{~h}$ in all horses. The $\mathrm{HD}_{\min }$ score then returned to baseline within $24 \mathrm{~h}$ after LPS-challenge in five horses and within $32 \mathrm{~h}$ in one horse. A pharmacodynamic model was fitted to experimental lameness response data from all horses. Experimental $\mathrm{HD}_{\text {min }}$ data were evenly distributed around the line of unity for both the structural and the random component of the pharmacodynamics model (Fig. 6). CWRES over time were concentrated between $\mathrm{y}=-2$ and $\mathrm{y}=+2$ for lameness data (Fig. 7). The model estimated typical values are shown in Table 3

\section{Discussion}

This study investigated and described dexamethasone disposition in synovial fluid and plasma after IA administration of DSP in the inflamed equine joint. Simultaneously it reports the relation between synovial fluid 


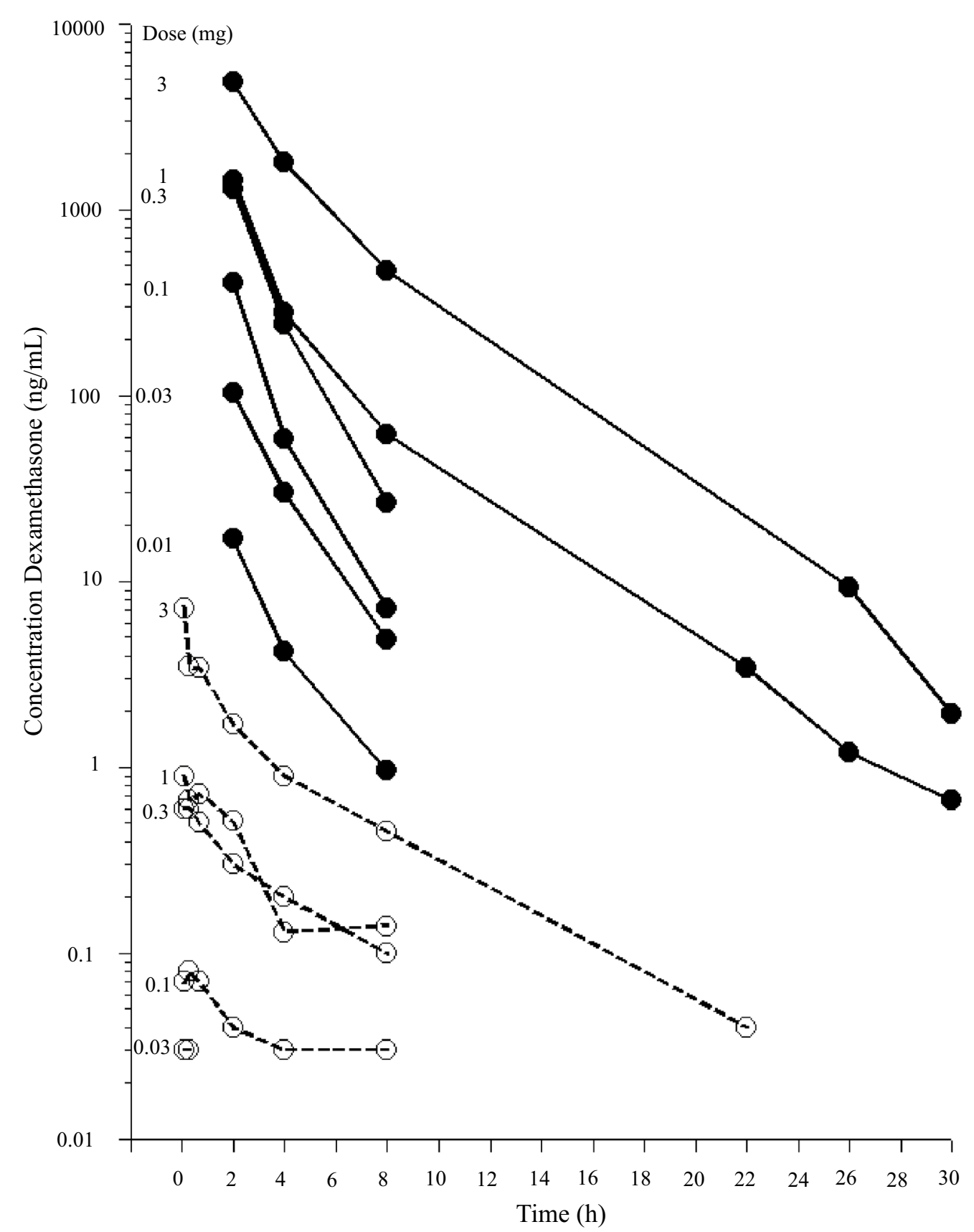

Fig. 2 Observed dexamethasone synovial fluid (filled circles) and plasma (open circles) concentrations over time after intra articular administration of dexamethasone sodium phosphate into the LPS-challenged joint

and plasma concentration and CE response to IA dexamethasone treatment. The present data were analysed with a NLME model (also known as population modelling) consistent with the U.S Food and Drug Administration guidelines [23]. The population PK approach allows the analysis of data from a variety of unbalanced designs as well as from studies that are normally excluded because they do not lend themselves to the usual forms of pharmacokinetic analysis, such as concentration data obtained from paediatric and elderly patients, or data obtained during the evaluation of the relationships between dose or concentration and efficacy or safety [26]. For our data sets, a classical two-stages analysis led to the biased estimate of some parameters as the $I C_{50}$ due to 
Table 2 Model typical values (tv) and the individual pharmacokinetic parameter estimates for the horses A-F

\begin{tabular}{llllllllll}
\hline Horse & Dose $(\mathbf{m g})$ & $\boldsymbol{V}_{\text {syn }}(\mathbf{m L} / \mathbf{k g})$ & $\boldsymbol{k}_{a p}(\mathbf{1} / \mathbf{h})$ & $\boldsymbol{k}_{\boldsymbol{p a}}(\mathbf{1} / \mathbf{h})$ & $\boldsymbol{k}_{\boldsymbol{e l}}(\mathbf{1} \mathbf{h})$ & $\boldsymbol{V}_{\boldsymbol{c}}(\mathbf{m L} / \mathbf{k g})$ & $\boldsymbol{V}_{\boldsymbol{t}}(\mathbf{m L} / \mathbf{k g})$ & $\boldsymbol{C l}(\mathbf{m L} / \mathbf{k g} / \mathbf{h})$ & $\boldsymbol{C l} \boldsymbol{d}_{\boldsymbol{d}}(\mathbf{m L} / \mathbf{k g} / \mathbf{h})$ \\
\hline tV & na & 0.2 & 0.6 & 0.15 & 0.010 & 338 & 1123 & 246 & 495 \\
F & 0.01 & 0.49 & 0.61 & 0.15 & 0.010 & 279 & 1135 & 247 & 491 \\
C & 0.03 & 0.27 & 0.61 & 0.14 & 0.011 & 148 & 1114 & 253 & 690 \\
B & 0.1 & 0.26 & 0.65 & 0.14 & 0.013 & 126 & 1018 & 266 & 778 \\
A & 0.3 & 0.18 & 0.74 & 0.15 & 0.009 & 85 & 997 & 417 & 598 \\
D & 1 & 0.20 & 1.06 & 0.15 & 0.010 & 308 & 1133 & 446 & 637 \\
E & 3 & 0.03 & 1.91 & 0.15 & 0.010 & 230 & 1263 & 470 & 763
\end{tabular}

Where $t v$ is the typical value for the population, dose is the amount dexamethasone administered into the joint, $V_{s y n}, V_{c}$ and $V_{t}$ are the volume of distribution in the synovial compartment (typical value was fixed to $0.2 \mathrm{~mL} / \mathrm{kg}$ ), the central compartment and the peripheral compartment, respectively. $C l$ is the plasma clearance and $C l_{d}$ is the inter-compartmental distribution parameter. $k_{a p}, k_{p a}$ and $k_{e l}$ are the rate constants from the joint to the plasma, the plasma to the joint and direct elimination from the joint, respectively. Note that shrinkage was high (>0.3) for $k_{a p}, k_{p a} k_{e l}, v_{s y n}$ and $C l$ due to a poor estimate of the random component of the model for these parameters and corresponding post hoc values were shrinked toward their population values

outlying individual estimate whereas the NLME-analyses allowed the estimate of robust typical (here synonym of mean) values of these parameters even if the between subject variability was not properly estimated for some parameters from our limited number of horses. This approach is also recommended in toxicokinetic trials for which a limited number of subject are often investigated using different unbalanced and sparsely sampling design [27, 28].

The pharmacokinetic model fitted to experimental synovial fluid dexamethasone data satisfactory mimicked the data and no major bias or model misspecifications were suspected (Figs. 3 and 4). Quantitative information about synovial fluid and plasma disposition of dexamethasone was provided (Table 2). To our knowledge, the dexamethasone concentration-time course in synovial fluid has not previously been reported. In plasma, the total clearance, the central and peripheral volume of distribution and the initial and terminal half-lives were consistent with the literature $[8,21,29,30]$. Dexamethasone was removed from the joint when synovial fluid was collected and possibly by enzymatic breakdown in the joint. The cumulative amount directly removed from the joint was $0.5-2.1 \%$ of the administered dose. This a suggest a systemic bioavailability around $98-99.5 \%$ for dexamethasone after IA injection in the inflamed joint, which is consistent with the bioavailability of dexamethasone after IA-administration in the healthy carpal joint [8]. The very low value for $k_{e l}$ indicate that the half-life of dexamethasone in inflamed synovial fluid is similar to the half-life in plasma (the $t_{1 / 2 \alpha}$ and $t_{1 / 2 \beta}$ in plasma was $0.6 \mathrm{~h}$ and $4.3 \mathrm{~h}$, respectively). This is consistent with our preliminary calculations of dexamethasone half-life in inflamed synovial fluid (terminal half-life: 0.9-3.3 h) published elsewhere [31]

In both experimental and clinical studies joint swelling and lameness has been used as biomarkers after intra-articular glucocorticoid therapy in horses $[3,4,6$, 7]. LPS-challenge has been used previously to induce inflammation in the equine joint [32-36]. Doses up to 2.5 ng LPS per joint caused a mild to moderate local joint inflammation that resolved within $36 \mathrm{~h}$, whereas doses above $125 \mathrm{ng}$ also caused signs of systemic inflammation. This study demonstrates between animal lameness $\left(\mathrm{HD}_{\text {min }}\right)$ variation after LPS challenge followed by saline injection (Fig. 5). This variation is not showed in the amplitude parameter, which is a consequence of the additional $\gamma_{1}$-parameter and $\gamma_{2}$-parameter. However, the $\gamma$-parameters were necessary to capture the peak and duration in lameness response. This was important to accurately fit the model to experimental data and estimation of model-parameters. Despite following strict procedures when injections were performed, incomplete intra-articular injection might have contributed to variation in response to the LPS-challenge and the dexamethasone treatment between the horses. Aspiration of synovial fluid followed by injection performed without resistance was used as confirmation of the needle placement within the joint cavity.

Lameness scores were lower after treatment with LPS + DSP than with LPS + saline. Five of the horses (Table 1) were treated with doses lower than the labelled dose 2-10 mg/joint [37]. In this study, the objective lameness assessment was a more sensitive method to evaluate lameness compared with the visual assessment. The inertial sensor based system has been validated for lameness detection and shown repeatability when used in a straight line as in this study and is comparable with optical based motion capture [20, 38, 39]. It has also been proposed that high intra- and interrater variability may bias and limit the usefulness of subjective lameness assessment [40-43]. The use of non-linear mixed effects model allowed fitting of a pharmacodynamic model to the sparse experimental objective lameness data and the 


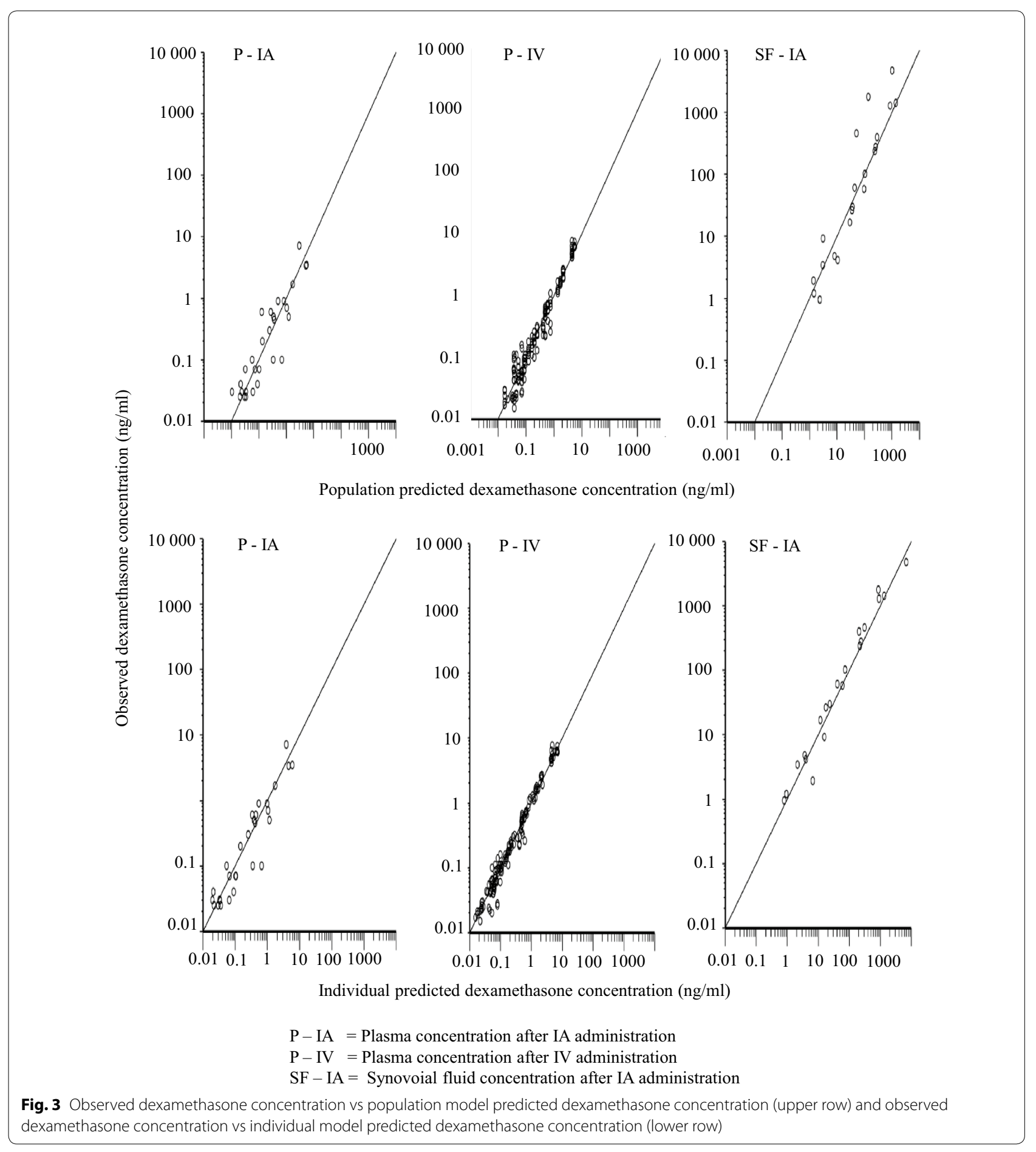

quantitative information of the pharmacodynamics was estimated (Figs. 6 and 7, Table 3). Both the dexamethasone synovial fluid potency $\left(I C_{50}\right)$ and efficacy $\left(I_{\text {max }}\right)$ values were derived as well as model parameters for the LPS-challenge. The $I C_{50}$ and $I_{\max }$ values are similar to what has been reported potency and efficacy values for glucose response in horses [44]. For all parameters for which the random component of the model was estimable, the BSV was relatively small (Tables 2 and 3). However, the shrinkage was high for the two pivotal pharmacodynamic parameters $\left(I C_{50}\right.$ and $\left.I_{\max }\right)$ indicating that the between subject variation for these two 


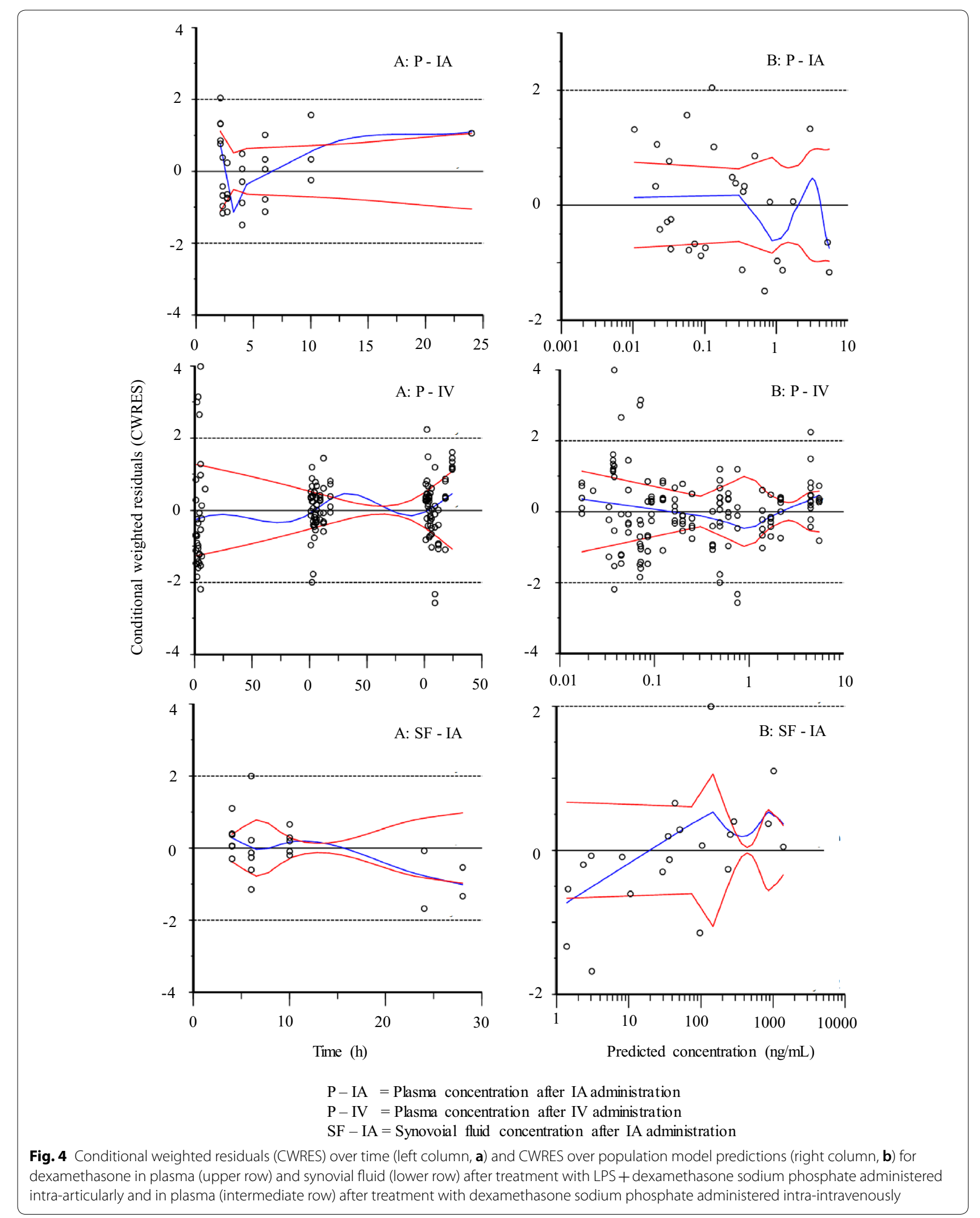



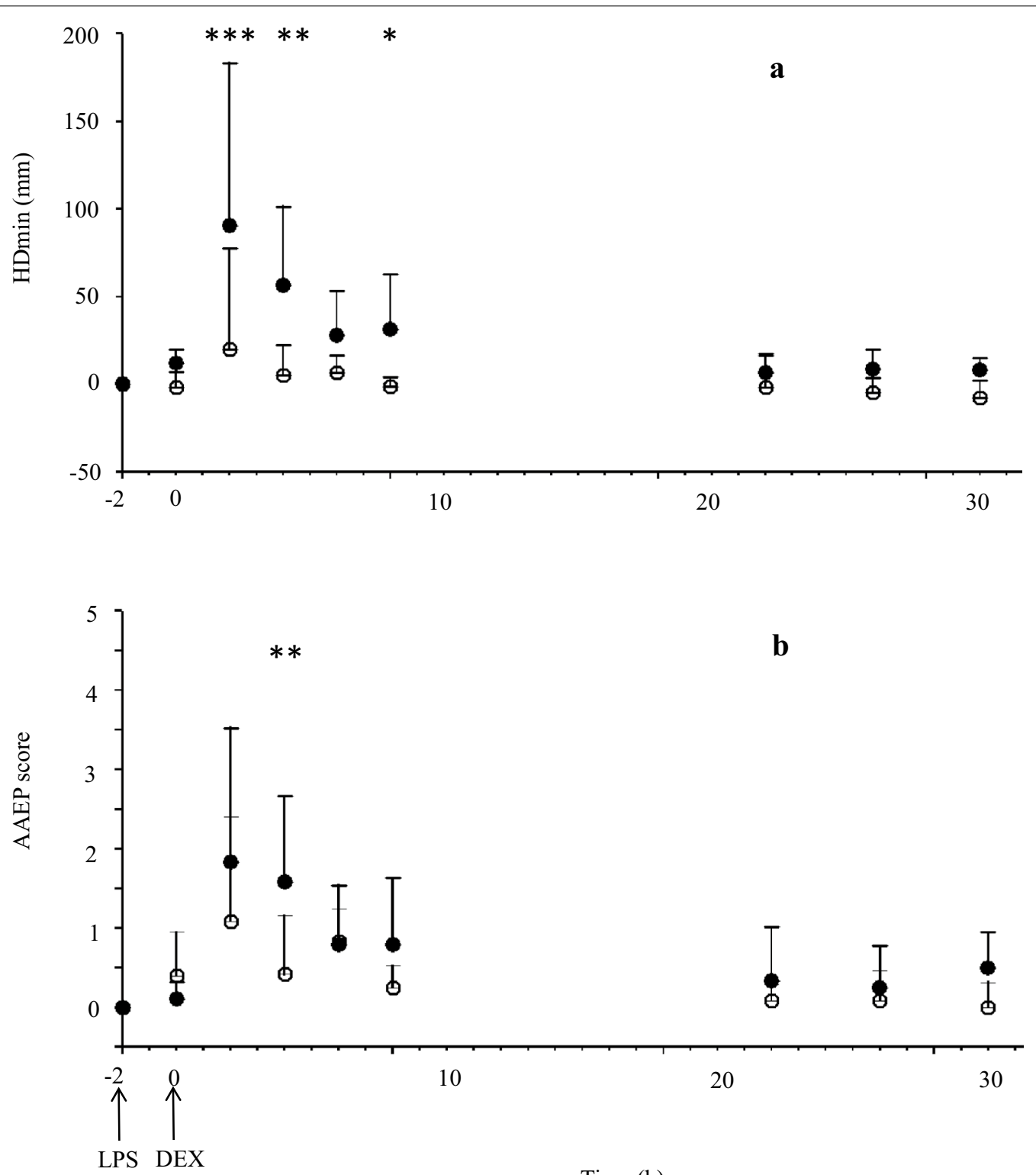

Time (h)

Significance levels between treatments: $*=P<0.05, * *=P<0.01, * * *=P<0.001$

Fig. 5 Change in (mean and standard deviation) lameness relative to baseline in six horses challenged with 2 ng lipopolysaccharides in the radiocarpal joint at hour - 2. At hour 0 either saline (filled circles) or dexamethasone (open circles) was injected in the LPS challenged joint. The horses received one dose dexamethasone sodium phosphate each. The doses were $0.01,0.03,0.1,0.3,1$, and $3 \mathrm{mg}$ administered in an injection volume of $2 \mathrm{~mL}$. Upper plot (a): change in minimum head height differences $\left(H D_{\min }\right)$ scored objectively. Lower pot $(\mathbf{b})$ : change in American Association of Equine Practitioners (AAEP) lameness score

parameters was not estimable from our data set and it was impossible to estimate accurate individual $I C_{50}$ and $I_{\max }$ (post hoc) values [24]. However we robustly estimated a typical value that should deserve attention.

Decreasing the dose may offer both benefits and disadvantages. Lower doses have lower risk for obvious systemic effects but also shorter duration of the local response in the joint. The use of lower doses may potentially increase the number of injections to uphold drug exposure over time. There are case reports describing septic arthritis following intra articular injections in the horse [45]. In the present study, totally 156 joint punctures were performed. There were no signs of septic arthritis during the study or in the following days. 


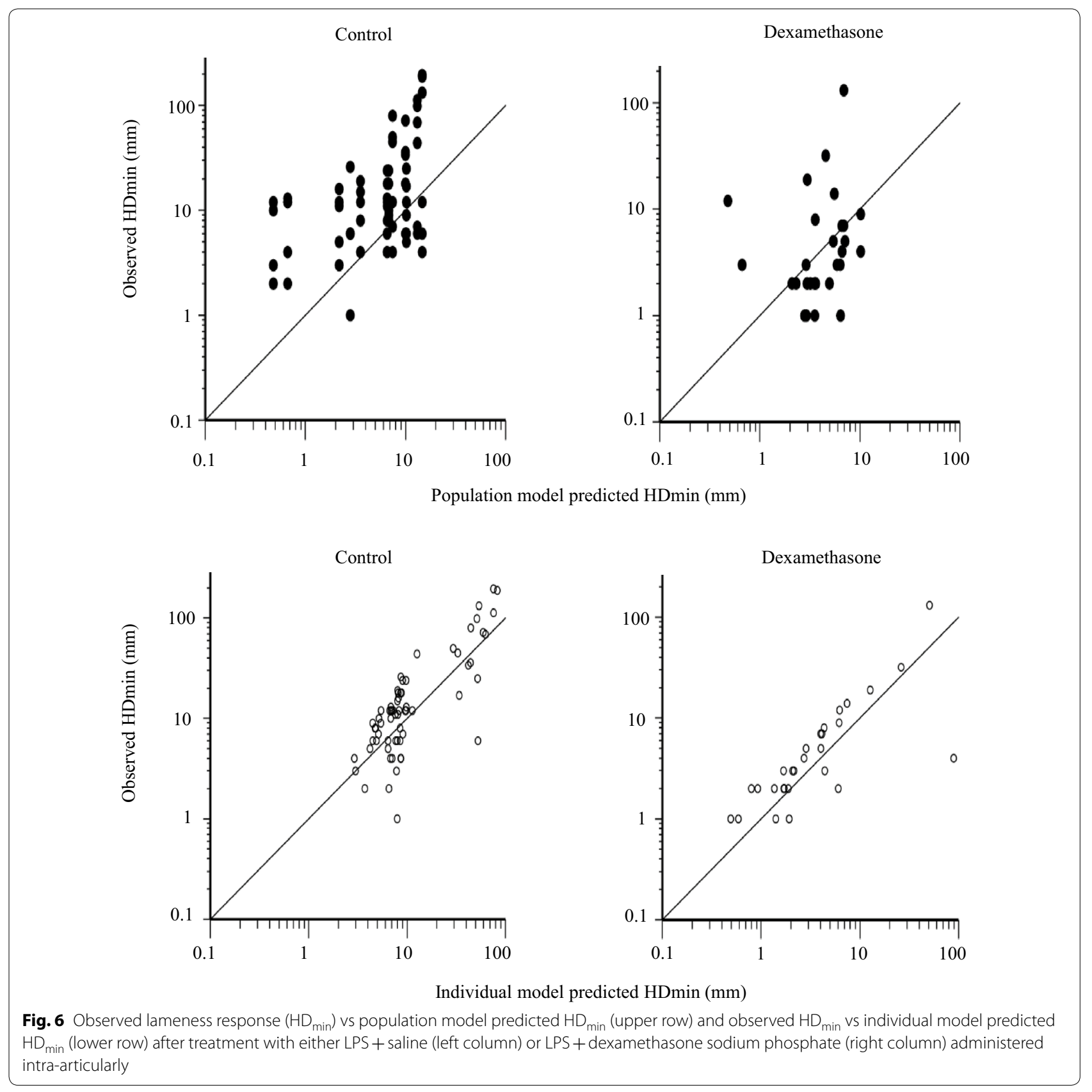

The result suggests that the risk for infection is low when aseptic injection techniques are used. This is also supported by a recent suggestion that infection is uncommon following joint injections [46]. However, septic arthritis is a severe condition and the risk should not be neglected. Higher doses would reduce the number of injections to maintain therapeutic concentrations in synovial fluid and consequently the risk for septic arthritis. However, there is some conflicting evidence for the risk of detrimental effects on articular cartilage at high glucocorticoid doses administered IA [47-49]. High doses also increase systemic exposure and might produce adverse systemic effects e.g. hyperglycaemia, hyperinsulinemia and potentially laminitis [50-52]. Further studies are warranted to evaluate if the benefit from lower doses outweigh the risks with repeated injections.

The variables JC (joint circumference) and ST (local skin temperature) were not statistically different between treatments. Both JC and ST have been used in response studies of anti-inflammatory drugs and there is 


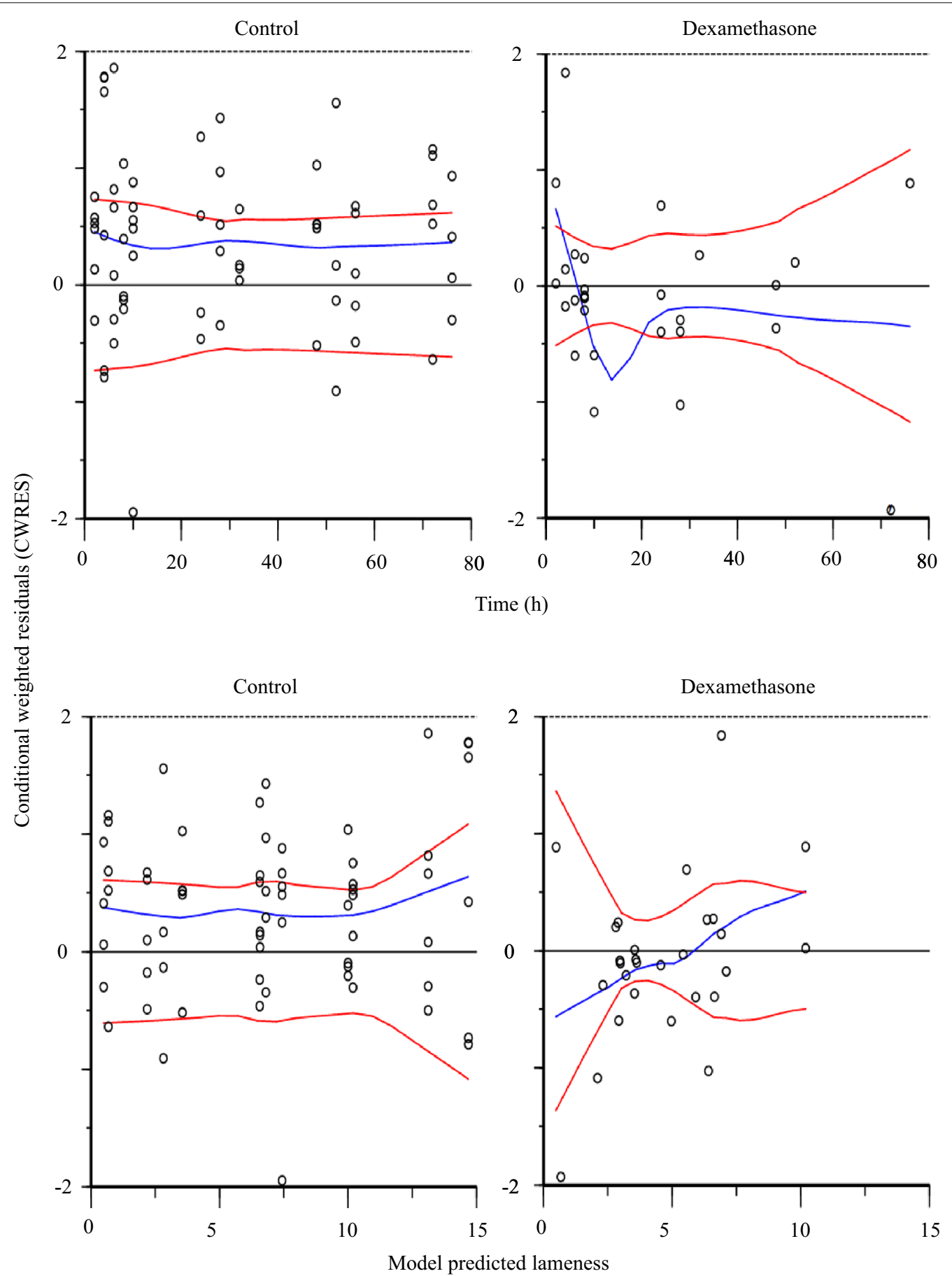

Fig. 7 Conditional weighted residuals (CWRES) over time (upper row) for and CWRES versus lameness response (lower row) after treatment with either LPS + saline (left column) or LPS + dexamethasone sodium phosphate (right column) administered intra-articularly

conflicting evidence for decrease in those variables. Morphine has anti-inflammatory properties and decreased ST and JC in equine synovitis [33]. Despite that nonsteroidal drugs might decrease ST, JC in horses or pawswelling in dogs may not decrease which suggest that JC may not be a suitable biomarker for the anti-inflammatory responses in acute synovitis [53-56]. A likely explanation for the non-significant results in ST in this study is the low dexamethasone exposure following the lowest doses used combined with the relatively low power 
Table 3 Model typical values (tv) and the individual pharmacodynamic parameter estimates for the horses A-F

\begin{tabular}{|c|c|c|c|c|c|c|c|c|c|c|}
\hline Horse & Dose (mg) & $I C_{50}(\mathrm{ng} / \mathrm{mL})$ & $I_{\max }$ & $k_{\text {out }}(1 / \mathrm{h})$ & $A_{L P S 1}(R / \mathrm{h})$ & $A_{\text {LPS2 }}(R / \mathrm{h})$ & $k_{\text {LPS1 }}(1 / \mathrm{h})$ & $k_{\text {LPS2 }}(1 / \mathrm{h})$ & $\gamma_{1}$ & $\gamma_{2}$ \\
\hline$t v$ & na & 4.0 & 0.84 & 0.44 & 3.5 & 48.4 & 0.04 & 0.65 & 3.9 & 0.8 \\
\hline $\mathrm{F}$ & 0.01 & 3.4 & 0.85 & 0.39 & 3.4 & 41.2 & 0.07 & 0.68 & 2.2 & 0.6 \\
\hline C & 0.03 & 2.9 & 0.85 & 0.59 & 3.4 & 43.3 & 0.06 & 0.68 & 1.6 & 0.6 \\
\hline B & 0.1 & 3.4 & 0.86 & 0.35 & 3.4 & 40.9 & 0.05 & 0.68 & 4.9 & 0.5 \\
\hline A & 0.3 & 3.1 & 0.85 & 0.39 & 3.4 & 47.5 & 0.007 & 0.69 & 12.8 & 1.5 \\
\hline D & 1 & 3.4 & 0.84 & 0.33 & 3.4 & 41.7 & 0.08 & 0.67 & 4.0 & 0.6 \\
\hline E & 3 & 3.9 & 0.85 & 0.39 & 3.4 & 41.2 & 0.07 & 0.68 & 2.1 & 0.6 \\
\hline
\end{tabular}

Where $t v$ is the typical value for the population, dose is the amount dexamethasone administered into the joint, $I C_{50}, I_{\text {max }}$ and $k_{\text {out }}$ are the potency value, the efficacy value (with a maximal possible value of 1 ) and fractional elimination rate of the response, respectively. $A_{L P S 1}, A_{L P S 2}, k_{L P S 1}, k_{L P S 2}, \gamma_{1}$ and $\gamma_{2}$ are maximal input rates, the rate constant controlling the time development of the challenge function and exponents shaping (amplifying) the response to the LPS-challenge, respectively. Note that shrinkage was high (>0.3) for $I C_{50} I_{\text {max }} A_{L P S 1}, A_{L P S 2}$ and $k_{L P S 2}$ due to a poor estimate of the random component of the model for these parameters and corresponding post hoc values were shrinked toward their population values

caused by study with only six horses. Consistent with this study significant lameness reduction and no decrease in JC after IA glucocorticoid administration has been reported elsewhere [4].

\section{Conclusion}

The synovial disposition and the response to dexamethasone were characterised in an equine model of synovitis after a single IA administration of DSP. The inertial sensor based lameness scoring system was the most sensitive of the methods used to evaluate the response to dexamethasone in this study. The presented quantitative information can be used as input for both future research and programs intended to upheld integrity and horse welfare in horseracing and equestrian sports. Dexamethasone synovial fluid half-life was considered similar to that in plasma. A tentative potency and efficacy value for lameness reduction was proposed. Lameness was suppressed after treatment with dexamethasone despite doses lower than labelled doses $(2-10 \mathrm{mg})$. Low doses of DSP combined with short half-life of dexamethasone in synovial fluid following IA administration will result in short duration of response, which must be considered in clinical treatment.

\section{Acknowledgements}

The authors wish to thank Professor Pierre-Louis Toutain for his great and invaluable assistance in data-analyses and for reading and commenting on the manuscript. We also send our gratitude to Rikstotoklinikken Bjerke AS for their co-operation during the study.

\section{Authors' contributions}

$\mathrm{CE}, \mathrm{Cl}-\mathrm{L}$ and $\mathrm{BR}$ planned the experiment. CE, CI-L, BR, EG, TS and LM performed the experiment and collected samples/data. CE, ML, MH, UB, MR and SJ performed laboratory work and data analyses. CE was main contributor to the manuscript. All authors revised the manuscript. All authors read and approved the final manuscript.

\section{Funding}

This study was funded by the Swedish-Norwegian Foundation for Equine Research.

\section{Availability of data and materials}

The datasets used and/or analysed during the current study are available from the corresponding author on reasonable request.

Ethics approval and consent to participate

The study was approved by the Norwegian Animal Research Authority (Forsøksdyrutvalget 2013/61618-1). The study originally published in [21] was approved by the Ethics Committee for Animal Experiments, Uppsala, Sweden (C333/11).

\section{Consent for publication}

Not applicable.

\section{Competing interests}

The authors declare that they have no competing interests.

\section{Author details}

${ }^{1}$ Department of Biomedical Sciences and Veterinary Public Health, Faculty of Veterinary Medicine and Animal Science, Swedish University of Agricultural Sciences, Box 7058, 75007 Uppsala, Sweden. ${ }^{2}$ Department of Chemistry, Environment and Feed Hygiene, National Veterinary Institute (SVA), 75189 Uppsala, Sweden. ${ }^{3}$ Department of Medicinal Chemistry, Faculty of Pharmacy, Uppsala University, Box 574, 75123 Uppsala, Sweden. ${ }^{4}$ Romerike Hesteklinikk, Riisveien 75, 2007 Kjeller, Norway. ${ }^{5}$ Department of Veterinary Clinical Sciences, Faculty of Health and Medical Sciences, University of Copenhagen, Dyrlægevej 16, 1870 Copenhagen, Frederiksberg C, Denmark. ${ }^{6}$ Department of Anatomy, Physiology and Biochemistry, Faculty of Veterinary Medicine and Animal Science, Swedish University of Agricultural Sciences, Box 7011, 75007 Uppsala, Sweden. ${ }^{7}$ Rikstotoklinikken Bjerke AS., Postboks 194, 0510, Oslo, Norway.

${ }^{8}$ Production Animal Clinical Science, Faculty for Veterinary Medicine, The Norwegian University of Life Sciences, Box 369 sentrum, 0102 Oslo, Norway.

Received: 14 August 2018 Accepted: 13 June 2019

Published online: 20 June 2019

\section{References}

1. Reed SR, Jackson BF, Mc Ilwraith CW, Wright IM, Pilsworth R, Knapp S, et al, Descriptive epidemiology of joint injuries in Thoroughbred racehorses in training. Equine Vet J. 2012:44:13-9.

2. Neundorf RH, Lowerison MB, Cruz AM, Thomason JJ, McEwen BJ, Hurtig MB. Determination of the prevalence and severity of metacarpophalangeal joint osteoarthritis in Thoroughbred racehorses via quantitative macroscopic evaluation. Am J Vet Res. 2010;71:1284-93.

3. Labens R, Mellor DJ, Voute LC. Retrospective study of the effect of intraarticular treatment of osteoarthritis of the distal tarsal joints in 51 horses. Vet Rec. 2007:161:611-6. 
4. Kay AT, Bolt DM, Ishihara A, Rajala-Schultz PJ, Bertone AL. Anti-inflammatory and analgesic effects of intra-articular injection of triamcinolone acetonide, mepivacaine hydrochloride, or both on lipopolysaccharideinduced lameness in horses. Am J Vet Res. 2008;69:1646-54.

5. Salles-Gomes TL, Canola JC, Almeida PE, Canola PA, Souza AH. The effects of intra-articular and intravenous dexamethasone tereoxiacetate administration in horses with intercarpal arthritis induced by injection of Escherichia coli lipopolysaccharide. Ars Vet. 2003;19:241-5 (in portugese).

6. de Grauw JC, Visser-Meijer MC, Lashley F, Meeus P, van Weeren PR. Intraarticular treatment with triamcinolone compared with triamcinolone with hyaluronate: a randomised open-label multicentre clinical trial in 80 lame horses. Equine Vet J. 2016;48:152-8.

7. Van Pelt RW, Tillotson PJ, Gertsen KE. Intra-articular injection of betamethasone in arthritis in horses. J Am Vet Med Assoc. 1970;156:1589-99.

8. Soma LR, Uboh CE, Liu Y, Li X, Robinson MA, Boston RC, et al. Pharmacokinetics of dexamethasone following intra-articular, intravenous, intramuscular, and oral administration in horses and its effects on endogenous hydrocortisone. J Vet Pharmacol Ther. 2013;36:181-91.

9. Soma LR, Uboh CE, Luo Y, Guan F, Moate PJ, Boston RC. Pharmacokinetics of methylprednisolone acetate after intra-articular administration and its effect on endogenous hydrocortisone and cortisone secretion in horses. Am J Vet Res. 2006;67:654-62.

10. Soma LR, Uboh CE, You Y, Guan F, Boston RC. Pharmacokinetics of intraarticular, intravenous, and intramuscular administration of triamcinolone acetonide and its effect on endogenous plasma hydrocortisone and cortisone concentrations in horses. Am J Vet Res. 2011;72:1234-42.

11. Menendez MI, Phelps MA, Bertone AL. Pharmacokinetics of intra-articular betamethasone sodium phosphate and betamethasone acetate and endogenous hydrocortisone suppression in exercising horses. J Vet Pharmacol Ther. 2016;39:22-6.

12. Menendez MI, Phelps MA, Hothem EA, Bertone AL. Pharmacokinetics of methylprednisolone acetate after intra-articular administration and subsequent suppression of endogenous hydrocortisone secretion in exercising horses. Am J Vet Res. 2012;73:1453-61.

13. Lillich JD, Bertone AL, Schmall LM, Ruggles AJ, Sams RA. Plasma, urine, and synovial fluid disposition of methylprednisolone acetate and isoflupredone acetate after intra-articular administration in horses. Am J Vet Res. 1996;57:187-92.

14. Knych HK, Harrison LM, Casbeer HC, McKemie DS. Disposition of methylprednisolone acetate in plasma, urine, and synovial fluid following intra-articular administration to exercised thoroughbred horses. J Vet Pharmacol Ther. 2014;37:125-32.

15. Knych HK, Vidal MA, Casbeer HC, McKemie DS. Pharmacokinetics of triamcinolone acetonide following intramuscular and intra-articular administration to exercised Thoroughbred horses. Equine Vet J. 2013;45:715-20.

16. Autefage A, Alvinerie M, Toutain PL. Synovial fluid and plasma kinetics of methylprednisolone and methylprednisolone acetate in horses following intra-articular administration of methylprednisolone acetate. Equine Vet $\mathrm{J}$. 1986;18:193-8.

17. Chen CL, Sailor JA, Collier J, Wiegand J. Synovial and serum levels of triamcinolone following intra-articular administration of triamcinolone acetonide in the horse. JVet Pharmacol Ther. 1992;15:240-6.

18. Wong JK, Wan TS. Doping control analyses in horseracing: a clinician's guide. Vet J. 2014;200:8-16.

19. Toutain PL, Lassourd V. Pharmacokinetic/pharmacodynamic approach to assess irrelevant plasma or urine drug concentrations in postcompetition samples for drug control in the horse. Equine Vet J. 2002;34:242-9.

20. Keegan KG, Kramer J, Yonezawa Y, Maki H, Pai PF, Dent EV, et al. Assessment of repeatability of a wireless, inertial sensor-based lameness evaluation system for horses. Am J Vet Res. 2011;72:1156-63.

21. Ekstrand C, Ingvast-Larsson C, Olsen L, Hedeland M, Bondesson U, Gabrielsson J. A quantitative approach to analysing cortisol response in the horse. J Vet Pharmacol Ther. 2016;39:255-63.

22. Ekstrand C, Bondesson U, Gabrielsson J, Hedeland M, Kallings P, Olsen $L$, et al. Plasma concentration-dependent suppression of endogenous hydrocortisone in the horse after intramuscular administration of dexamethasone-21-isonicotinate. J Vet Pharmacol Ther. 2015;38:235-42.

23. U.S Food and Drug Administration. guidance for industry population pharmacokinetics. https://www.fda.gov/downloads/Drugs/GuidanceCo mplianceRegulatorylnformation/Guidances/UCM072137.pdf. Accessed 04 Mar 2019.
24. Karlsson MO, Savic RM. Diagnosing model diagnostics. Clin Pharm Ther. 2007;82:17-20.

25. Zhang L, Beal SL, Sheiner LB. Simultaneous vs. sequential analysis for population PK/PD data I: best-case performance. J Pharmacokinet Pharmacodyn. 2003;30:387-404.

26. Aarons L. Sparse data analysis. Eur J Drug Metab Pharmacokinet. 1993;18:97-100.

27. Aarons L, Graham G. Methodological approaches to the population analysis of toxicity data. Toxicol Lett. 2001;120:405-10.

28. Hing JP, Woolfrey SG, Greenslade D, Wright PM. Is mixed effects modeling or naive pooled data analysis preferred for the interpretation of single sample per subject toxicokinetic data? J Pharmacokinet Pharmacodyn. 2001:28:193-210.

29. Grady JA, Davis EG, KuKanich B, Sherck AB. Pharmacokinetics and pharmacodynamics of dexamethasone after oral administration in apparently healthy horses. Am J Vet Res. 2010;71:831-9.

30. Soma LR, Uboh CE, Luo Y, Guan F, Moate PJ, Boston RC. Pharmacokinetics of dexamethasone with pharmacokinetic/pharmacodynamic model of the effect of dexamethasone on endogenous hydrocortisone and cortisone in the horse. J Vet Pharmacol Ther. 2005;28:71-80.

31. Ekstrand C, Ingvast-Larsson C, Bondesson U, Hedeland M, Ranheim B. Disposition of dexamethasone in the inflamed equine joint. In: Proceedings from 21 st international conference of racing analyists and veterinarians. 2016. p. 510-5.

32. Palmer JL, Bertone AL. Experimentally-induced synovitis as a model for acute synovitis in the horse. Equine Vet J. 1994;26:492-5.

33. Lindegaard C, Gleerup KB, Thomsen MH, Martinussen T, Jacobsen S, Andersen PH. Anti-inflammatory effects of intra-articular administration of morphine in horses with experimentally induced synovitis. Am J Vet Res. 2010;71:69-75.

34. Jacobsen S, Niewold TA, Halling-Thomsen M, Nanni S, Olsen E, Lindegaard $C$, et al. Serum amyloid $A$ isoforms in serum and synovial fluid in horses with lipopolysaccharide-induced arthritis. Vet Immunol Immunopathol. 2006;110:325-30

35. Campebell RC, Peiro JR, Valadao CAA, Santana AE, Cunha FQ. Effects of lidocaine on lipopolysaccharide-induced synovitis in horses. Arq Bras Med Vet Zoo. 2004;56:281-91.

36. Easter $L$, Watkins JP, Stephens SL, Carter GK, Hague BA et al. Effects of regional anesthesia on experimentally induced coffin joint synovitis. In: Proceeding of the annual convention of the AAEP. 2000. p. 214-6.

37. Medical Products Agency. Dexaject solution for injection. Summary of product characteristics. 2015. https://docetp.mpa.se/LMF/Dexaject\%20 solution\%20for\%20injection\%20SmPC_09001 be6803f053c.pdf. Accessed 20 June 2018.

38. Keegan KG, Yonezawa Y, Pai PF, Wilson DA, Kramer J. Evaluation of a sensor-based system of motion analysis for detection and quantification of forelimb and hind limb lameness in horses. Am J Vet Res. 2004;65:665-70.

39. Kelmer G, Keegan KG, Kramer J, Wilson DA, Pai FP, Singh P. Computerassisted kinematic evaluation of induced compensatory movements resembling lameness in horses trotting on a treadmill. Am J Vet Res. 2005:66:646-55.

40. Hewetson M, Christley RM, Hunt ID, Voute LC. Investigations of the reliability of observational gait analysis for the assessment of lameness in horses. Vet Rec. 2006;158:852-7.

41. Keegan KG, Wilson DA, Wilson DJ, Smith B, Gaughan EM, Pleasant RS, et al. Evaluation of mild lameness in horses trotting on a treadmill by clinicians and interns or residents and correlation of their assessments with kinematic gait analysis. Am J Vet Res. 1998;59:1370-7.

42. Arkell M, Archer RM, Guitian FJ, May SA. Evidence of bias affecting the interpretation of the results of local anaesthetic nerve blocks when assessing lameness in horses. Vet Rec. 2006;159:346-9.

43. Hammarberg M, Egenvall A, Pfau T, Rhodin M. Rater agreement of visual lameness assessment in horses during lungeing. Equine Vet $\mathrm{J}$. 2016:48:78-82

44. Ekstrand C, Falkenö U, Kallings P, Tvedten H, Lilliehöök I. Plasma dexamethasone concentration in relation to glucose response in the horse. $J$ Equine Vet Sci. 2019;73:75-80.

45. Lapointe JM, Laverty S, Lavoie JP. Septic arthritis in 15 standardbred racehorses after intra-articular injection. Equine Vet J. 1992;24:430-4. 
46. Steel CM, Pannirselvam RR, Anderson GA. Risk of septic arthritis after intra-articular medication: a study of 16,624 injections in Thoroughbred racehorses. Aust Vet J. 2013;91:268-73.

47. Richardson DW, Dodge GR. Dose-dependent effects of corticosteroids on the expression of matrix-related genes in normal and cytokine-treated articular chondrocytes. Inflamm Res. 2003;52:39-49.

48. Dechant JE, Baxter GM, Frisbie DD, Trotter GW, Mcllwraith CW. Effects of dosage titration of methylprednisolone acetate and triamcinolone acetonide on interleukin-1-conditioned equine articular cartilage explants in vitro. Equine Vet J. 2003;35:444-50.

49. Murphy DJ, Todhunter RJ, Fubini SL, Vernier-Singer M, Straubinger RK, Lust G. The effects of methylprednisolone on normal and monocyteconditioned medium-treated articular cartilage from dogs and horses. Vet Surg. 2000:29:546-57.

50. Tiley HA, Geor RJ, McCutcheon LJ. Effects of dexamethasone on glucose dynamics and insulin sensitivity in healthy horses. Am J Vet Res. 2007;68:753-9.

51. Bailey SR. Corticosteroid-associated laminitis. Vet Clin N Am Equine Pract. 2010;26:277-85.

52. Welsh CE, Duz M, Parkin TDH, Marshall JF. Disease and pharmacologic risk factors for first and subsequent episodes of equine laminitis: a cohort study of free-text electronic medical records. Prev Vet Med. 2017;136:11-8.
53. Toutain PL, Autefage A, Legrand C, Alvinerie M. Plasma concentrations and therapeutic efficacy of phenylbutazone and flunixin meglumine in the horse: pharmacokinetic/pharmacodynamic modelling. J Vet Pharmacol Ther. 1994;17:459-69.

54. de Grauw JC, van de Lest CH, Brama PA, Rambags BP, van Weeren PR. In vivo effects of meloxicam on inflammatory mediators, MMP activity and cartilage biomarkers in equine joints with acute synovitis. Equine Vet J. 2009;41:693-9.

55. Toutain PL, Cester CC. Pharmacokinetic-pharmacodynamic relationships and dose response to meloxicam in horses with induced arthritis in the right carpal joint. Am J Vet Res. 2004;65:1533-41.

56. Jeunesse EC, Bargues IA, Toutain CE, Lacroix MZ, Letellier IM, Giraudel JM, et al. Paw inflammation model in dogs for preclinical pharmacokinetic/ pharmacodynamic investigations of nonsteroidal anti-inflammatory drugs. J Pharmacol Exp Ther. 2011;338:548-58.

\section{Publisher's Note}

Springer Nature remains neutral with regard to jurisdictional claims in published maps and institutional affiliations.
Ready to submit your research? Choose BMC and benefit from:

- fast, convenient online submission

- thorough peer review by experienced researchers in your field

- rapid publication on acceptance

- support for research data, including large and complex data types

- gold Open Access which fosters wider collaboration and increased citations

- maximum visibility for your research: over 100M website views per year

At BMC, research is always in progress.

Learn more biomedcentral.com/submissions 